Article

\title{
Pharmacokinetics of a Long-Acting Formulation of Oxytetracycline in Freshwater Crocodiles (Crocodylus siamensis) after Intramuscular Administration at Three Different Dosages
}

\author{
Saranya Poapolathep ${ }^{1}$, Narumol Klangkaew ${ }^{1}$, Napasorn Phaochoosak ${ }^{1}$, Tara Wongwaipairoj ${ }^{2}$, \\ Mario Giorgi ${ }^{3}$, Narongsak Chaiyabutr ${ }^{4}$, Darren J. Trott ${ }^{5}$ and Amnart Poapolathep ${ }^{1, *(1)}$ \\ 1 Department of Pharmacology, Faculty of Veterinary Medicine, Kasetsart University, \\ Bangkok 10900, Thailand; fvetsys@ku.ac.th (S.P.); fvetnak@ku.ac.th (N.K.); fvetanp@ku.ac.th (N.P.) \\ 2 Wongveerakit Crocodile Farm, Bo Phloi, Kanjanaburi 71160, Thailand; tara.wongwai@gmail.com \\ 3 Department of Veterinary Science, University of Pisa, 56112 Pisa, Italy; mario.giorgi@unipi.it \\ 4 Department of Physiology, Faculty of Veterinary Science, Chulalongkorn University, \\ Bangkok 10330, Thailand; narongsak.c@chula.ac.th \\ 5 Australian Centre for Antimicrobial Resistance Ecology, School of Animal and Veterinary Science, \\ University of Adelaide, Roseworthy 5371, Australia; darren.trott@adelaide.edu.au \\ * Correspondence: fvetamp@ku.ac.th; Tel.: +66-2-579-7537
}

Received: 4 June 2020; Accepted: 24 July 2020; Published: 27 July 2020

Simple Summary: The oxytetracycline long-acting formulation (OTC-LA) is used to treat sensitive pathogenic bacteria in the freshwater crocodile, Crocodylus siamensis. The pharmacokinetic profiles of differential dosages of OTC after intramuscular administration were investigated to determine the appropriate dosage for the treatment of bacterial infections in freshwater crocodiles. In freshwater crocodiles, dosages of 10 and $20 \mathrm{mg} / \mathrm{kg}$ produced OTC plasma concentrations higher than $2.0 \mu \mathrm{g} / \mathrm{mL}$ as a minimum inhibitory concentration (MIC) for $192 \mathrm{~h}$ and $216 \mathrm{~h}$ after intramuscular administration, respectively, while the OTC plasma concentration remained below the MIC of $2.0 \mu \mathrm{g} / \mathrm{mL}$ at a dosage of $5 \mathrm{mg} / \mathrm{kg}$ body weight (b.w.). When considering plasma protein binding of $32 \%$, an intramuscular (i.m.) administration at a dosage of $10 \mathrm{mg} / \mathrm{kg}$ b.w. might be effective for two weeks to treat sensitive pathogenic bacteria in freshwater crocodiles.

Abstract: To date, the necessary pharmacokinetic information has been limited to establish suitable therapeutic plans for freshwater crocodiles. Therefore, this study was conducted to evaluate the pharmacokinetic profile of the oxytetracycline long-acting formulation (OTC-LA) in the freshwater crocodile, Crocodylus siamensis, following a single intramuscular (i.m.) administration at three different dosages of 5,10 and $20 \mathrm{mg} / \mathrm{kg}$ body weight (b.w.). Blood samples were collected at assigned times up to $216 \mathrm{~h}$ after i.m. administration at the three different dosages. The plasma concentrations of OTC were measured using a validated liquid chromatography tandem-mass spectrometry (LC-MS/MS) method. The $\mathrm{C}_{\max }( \pm \mathrm{SD}$ ) values of OTC were $2.15 \pm 0.51 \mu \mathrm{g} / \mathrm{mL}, 7.68 \pm 1.08 \mu \mathrm{g} / \mathrm{mL}$ and $17.08 \pm 2.09 \mu \mathrm{g} / \mathrm{mL}$ at doses of 5,10 and $20 \mathrm{mg} / \mathrm{kg}$ b.w., respectively. The elimination half-life values were $33.59 \pm 2.51 \mathrm{~h}, 38.42 \pm 5.47 \mathrm{~h}$ and $38.04 \pm 1.98 \mathrm{~h}$ at dosages of 5,10 and $20 \mathrm{mg} / \mathrm{kg}$ b.w., respectively. Based on the pharmacokinetic data, the pharmacokinetic/pharmacodynamic (PK/PD) index, the susceptibility break-point and plasma protein binding, a dosage once every two weeks of $10 \mathrm{mg} / \mathrm{kg} \mathrm{b.w.} \mathrm{OTC} \mathrm{intramuscularly} \mathrm{might} \mathrm{be} \mathrm{suitable} \mathrm{for} \mathrm{initiating} \mathrm{the} \mathrm{treatment} \mathrm{of} \mathrm{susceptible}$ bacterial infections in freshwater crocodiles. However, further PK/PD studies are warranted to confirm whether the dose rates used in this study can produce longer-term antimicrobial success for diseases caused by susceptible bacteria in freshwater crocodiles. 
Keywords: oxytetracycline; pharmacokinetics; freshwater crocodiles; LC-MS/MS

\section{Introduction}

Oxytetracycline (OTC), a tetracycline derivative obtained from Streptomyces rimosus, is a broad-spectrum antibiotic used against a variety of pathogens, including bacteria, mycoplasma, rickettsia, chlamydiae and even some protozoa [1]. OTC is a bacteriostatic antibiotic that inhibits protein synthesis by reversibly binding to the $30 \mathrm{~S}$ ribosomal subunit of a susceptible organism [2]. The antibacterial efficacy of OTC is described as time-dependent. OTC is distributed rapidly and extensively in animal body fluids and tissues, undergoes enterohepatic recirculation in some mammals and is then excreted primarily by glomerular filtration and biliary elimination [3].

One of the major obstacles to the successful treatment of infectious diseases in freshwater crocodile species is the incorrect dosing of antibiotics. When drugs are administered at subtherapeutic levels, there is an increased risk of therapeutic failure or the development of bacterial resistance or both. The treatment of bacterial infections should be based on a rational scientific approach, which, in the case of antibiotics, is the pharmacokinetic/pharmacodynamic (PK/PD) approach. In breeding farms, crocodile mortality is often directly related to infectious diseases precipitated by stress [4]. Currently, there are few reports on the pharmacokinetics and dosage regimen of antimicrobial drugs in crocodiles. Regarding pharmacokinetic profiles, a number of antimicrobial drugs have been investigated in American alligators, estuarine crocodiles and freshwater crocodiles [5-11].

Long-acting formulations of antimicrobial agents are advantageous for the clinical treatment of dangerous animal species. Thus, it is valuable to examine whether therapeutic concentrations of OTC can be maintained for a long period in freshwater crocodiles. The term "long-acting" implies that the formulation provides a prolonged circulation of antibacterial concentrations of the active agent and should show a commensurate improvement in clinical efficacy [12]. In American alligators, therapeutic plasma concentrations of OTC were maintained for seven days after intramuscular (i.m.) administration at a dosage of $10 \mathrm{mg} / \mathrm{kg}$ body weight (b.w.) [5]. Therefore, the aim of this study was to evaluate the pharmacokinetic profiles of a long-acting formulation of oxytetracycline (OTC-LA) in the freshwater crocodile, Crocodylus siamensis, following an intramuscular (i.m.) administration at three different dosages of 5,10 and $20 \mathrm{mg} / \mathrm{kg}$ b.w.

\section{Materials and Methods}

\subsection{Animals}

Fifteen freshwater crocodiles, C. siamensis (females, aged 2.5-3.2 years, body weights of 14.8-20.4 kg and lengths of 140-166 cm), were used in the study. All 15 experimental farmed crocodiles were housed in cement ponds at Wongveerakit Farm, Bo Phloi Kanchanaburi Province, Thailand. The cement pond area is $5 \mathrm{~m}$ (wide) and $10 \mathrm{~m}$ (length), including slope and shelter. Five experimental crocodiles were house per each pond. The water was changed every day through the experimental period to clear the excreted drug and waste. All experimental procedures were performed according to the Guidelines for Animal Experiments and approved by the Animal Ethics Research Committee of the Faculty of Veterinary Medicine, Kasetsart University, Bangkok, Thailand. The experiment was conducted within an environmental temperature range of $27-33{ }^{\circ} \mathrm{C}$. Prior to inclusion in the study, each animal was deemed healthy based on their health history, physical examination and complete blood count analysis, all of which were performed within 2 days of the commencement of the study. Body weights for the purpose of the dose calculation were acquired no more than $48 \mathrm{~h}$ prior to drug administration. 


\subsection{Drugs and Chemicals}

Oxytetracycline-long acting formulation (Terramycin/LA ${ }^{\circledR}$ ) for injection was purchased from Zoetis (Zoetis Inc., New Jersey, NJ. USA). OTC of analytical standard was purchased from Sigma Chemical Co. (St. Louis, MO, USA). Other reagents and chemicals of analytical grade were purchased from Sigma Chemical Co. (St. Louis, MO, USA). Purified water was produced using the Milli-Q water purification system from Millipore, Inc. (Bedford, MA, USA). OTC was dissolved with $0.01 \%$ formic acid in $50 \%$ acetonitrile solution for spiked samples and calibration.

\subsection{Experimental Design}

The 15 crocodiles were weighed and identified using a permanent numbered marker on the back region of the head and divided into three groups $(n=5)$ using a randomization procedure according to a parallel study design. Groups 1, 2 and 3 were administered OTC-LA i.m. at dosages of 5, 10 and $20 \mathrm{mg} / \mathrm{kg}$ b.w., respectively. The dose rates used in this study were based on preliminary studies in the target species and a previous study in American alligators [5]. Animals were manually restrained for the blood collection period between dosing, and two hours later, animals were left tied with their eyes covered to calm them. For the later blood collections, animals were released and recaptured. The i.m. dosing was delivered into the left biceps using a 22 gauge, 1.5-inch-long needle. The injection site was disinfected using ethyl alcohol prior to injection. The i.m. injection site was selected to avoid the renal portal system first-pass effect. Blood samples $(1.5-2.0 \mathrm{~mL})$ were collected from the tail vein of each animal in heparinized tubes at 0, 5, 15 and $30 \mathrm{~min}$ and at 1, 2, 4, 6, 8, 12, 24, 48, 72, 96, 120, 144, 168, 192 and $216 \mathrm{~h}$ after drug administration. The plasma was separated using centrifugation $(1986 \times \mathrm{g})$ for $15 \mathrm{~min}$, harvested and immediately stored at $-20^{\circ} \mathrm{C}$ for 2 weeks before analysis.

\subsection{Sample Extraction Procedure}

The OTC extraction method was performed as previously described $[13,14]$ and revalidated in spiked plasma of the crocodiles. Briefly, $500 \mu \mathrm{L}$ of freshwater crocodile plasma was deproteinated by adding $50 \mu \mathrm{L}$ of $15 \%$ trichloroacetic acid in acetonitrile (ACN) in a 1-mL conic Eppendorf tube and then vortexed for $1 \mathrm{~min}$. The mixture was centrifuged at $7168 \times \mathrm{g}$ for $15 \mathrm{~min}$ at $4{ }^{\circ} \mathrm{C}$. The supernatant was collected into new plastic vials. The supernatant was collected, passed through a $0.22-\mu \mathrm{m}$ nylon syringe filter and subjected to liquid chromatography-tandem mass spectrometry (LC-MS/MS).

\subsection{LC Parameters}

The LC analysis was performed using an Agilent 1200 series system consisting of a binary high-pressure-gradient pump, a vacuum solvent degassing unit, an automatic sample injector and a column thermostat (Agilent Technologies, Waldbronn, Germany). Separation was achieved using a ZORBAX Eclipse Plus Rapid Resolution HT (RRHT) C18 column $(4.6 \times 50$ mm, 1.8- $\mu \mathrm{m}$ particle size, Agilent Technologies) with a guard column $(4.6 \times 5 \mathrm{~mm}, 1.8-\mu \mathrm{m}$ particle size, Agilent Technologies). The column was maintained at a temperature of $35^{\circ} \mathrm{C}$. The LC mobile phase program consisted of a binary gradient of $0.1 \%$ formic acid in Milli-Q water (mobile phase A) and acetonitrile (mobile phase B). The gradient conditions were: 0-6.0 min, from $95 \%$ to $35 \% \mathrm{~A}, 6.0-7.0 \mathrm{~min}, 5 \% \mathrm{~A}, 7.0-10.0 \mathrm{~min}, 5 \% \mathrm{~A}$ and $10.0-11.0 \mathrm{~min}$, from $5 \%$ to $95 \% \mathrm{~A}$, followed by re-equilibration at $95 \% \mathrm{~A}$ until $15 \mathrm{~min}$. The flow rate was $400 \mu \mathrm{L} / \mathrm{min}$, and the injection volume was $5 \mu \mathrm{L}$.

\subsection{MS Parameters}

Mass spectrometry was performed using an Agilent Technologies 6460 triple quadrupole mass spectrometer equipped with an electrospray ionization (ESI) source and Agilent Mass Hunter Workstation Software version 1.2 (Agilent Technologies, Waldbronn, Germany). ESI-MS/MS was operated at unit mass resolution in the multiple reaction monitoring positive ion mode with the following settings: nebulizer gas pressure $45 \mathrm{psi}$, gas flow $5.0 \mathrm{~L} / \mathrm{min}$, gas temperature $300^{\circ} \mathrm{C}$, sheath gas 
temperature $380{ }^{\circ} \mathrm{C}$, sheath gas flow $10 \mathrm{~L} / \mathrm{min}$ and capillary voltage $3500 \mathrm{~V}$. The following transitions were used: OTC: $m / z 461.0>443.0$ and $461.0>426.0$.

\subsection{Validation Procedure}

The calibration standard concentrations were prepared by spiking the working standard solution into crocodile blank plasma to yield final concentrations of $0.05,0.1,0.5,1,5,10$ and $20 \mu \mathrm{g} / \mathrm{mL}$. The coefficient of determination $\left(r^{2}\right)$ value of the OTC calibration curves was 0.999. Seven duplicates of the quality control (QC) sample at concentrations of $0.1,1,10$ and $20 \mu \mathrm{g} / \mathrm{mL}$ were prepared and used to determine the recoveries, intra-day and inter-day precision and accuracy of the method. The procedure was repeated five times within the same day to gain intra-day run precision and accuracy and five times for each concentration over five different days to obtain inter-day run precision and accuracy. The extraction recoveries were $86.82 \% \pm 3.42 \%, 89.66 \% \pm 4.12 \%, 92.82 \% \pm 2.45 \%$ and $95.42 \% \pm 2.12 \%$ for $0.1,1,10$ and $20 \mu \mathrm{g} / \mathrm{mL}$, respectively. The inter-day precision and accuracy ranged from $3.42 \%$ to $6.88 \%$ and from 92.65 to $98.26 \%$, respectively. Levels for the limit of detection (LOD) and the limit of quantification (LOQ) of OTC were 0.01 and $0.05 \mu \mathrm{g} / \mathrm{mL}$, respectively.

\subsection{Plasma Protein Binding Assay}

Protein biding was determined using ultracentrifugation (Optima ${ }^{\mathrm{TM}}$ Max-XP, Beckman Coulter, Inc.,Indianapolis, IN, USA) [15]. Fresh OTC-free plasma samples from the freshwater crocodiles and phosphate-buffered saline were added to known concentrations of OTC, ranging from 1 to $10 \mu \mathrm{g} / \mathrm{mL}$. Samples were centrifuged at $480,000 \times g$ for $2.5 \mathrm{~h}$. Each plasma sample and its corresponding ultrafiltrate were assayed using LC-MS/MS, as described above. The percentage of the plasma protein-binding fraction was calculated according to the following equation:

Protein binding $(\%)=$ total concentration-ultrafiltrate concentration/total concentration $(\times 100)$

\subsection{Pharmacokinetic Analysis}

The concentration of OTC in experimental crocodiles with respect to time was analyzed using a noncompartmental model (ThothPro ${ }^{\mathrm{TM}} 4.3 .0 \mathrm{v}$ software, ThothPro LLC, Poland). The elimination half-life $\left(\mathrm{t}_{1 / 2 \lambda z}\right)$ was calculated using a nonlinear least squares regression analysis of the concentration-time curve, and the areas under the curve (AUC) were calculated using the linear-up $\log$-down rule to the final concentration time point $(\mathrm{Ct})$. From these values, the mean residence time (MRT = AUMC/AUC), $\mathrm{C}_{\max } /$ dose and $\mathrm{AUC} /$ dose were determined. Individual values between $\mathrm{AUC}_{0-\infty}$ and $\mathrm{AUC}_{0-\mathrm{t}}$ were lower than $20 \%$ of $\mathrm{AUC}_{0-\infty}$, with $r^{2}>0.85$ for the terminal phase regression line (at least 3 points were used for this latter estimation).

\subsection{Statistical Analysis}

Pharmacokinetic variables were evaluated using one-way ANOVA analysis and the Tukey's test for multiple comparisons to determine statistically significant differences among groups. Both pharmacokinetic parameters and OTC plasma concentrations were presented as mean \pm SD (normality tested using the Shapiro-Wilk test). All analyses were conducted using GraphPad Prism version 5.0 (GraphPad Software, La Jolla, CA, USA). Differences were considered significant for $p<0.05$.

\section{Results}

No adverse effects at the point of injection and no behavioral or health alterations were observed in the experimental animals during or after i.m. administration of OTC at the three different dosages.

OTC was quantifiable up to $216 \mathrm{~h}$ in all treated groups. The plots of the mean plasma concentration-time curves of OTC are displayed in Figure 1. The pharmacokinetic profiles had a double peak in all the animals, irrespective of treatment. The first peak appeared at 1.0, 0.5 and $0.5 \mathrm{~h}$ after i.m. administration at dosages of 5,10 and $20 \mathrm{mg} / \mathrm{kg}$ b.w., respectively. After rapid absorption 
followed by a significant decline in the concentration, a second peak was observed at $48 \mathrm{~h}$ after dosages of 5 and $10 \mathrm{mg} / \mathrm{kg}$ b.w. and at $24 \mathrm{~h}$ after a dosage of $20 \mathrm{mg} / \mathrm{kg} \mathrm{b.w}$. The plasma of OTC then gradually declined.

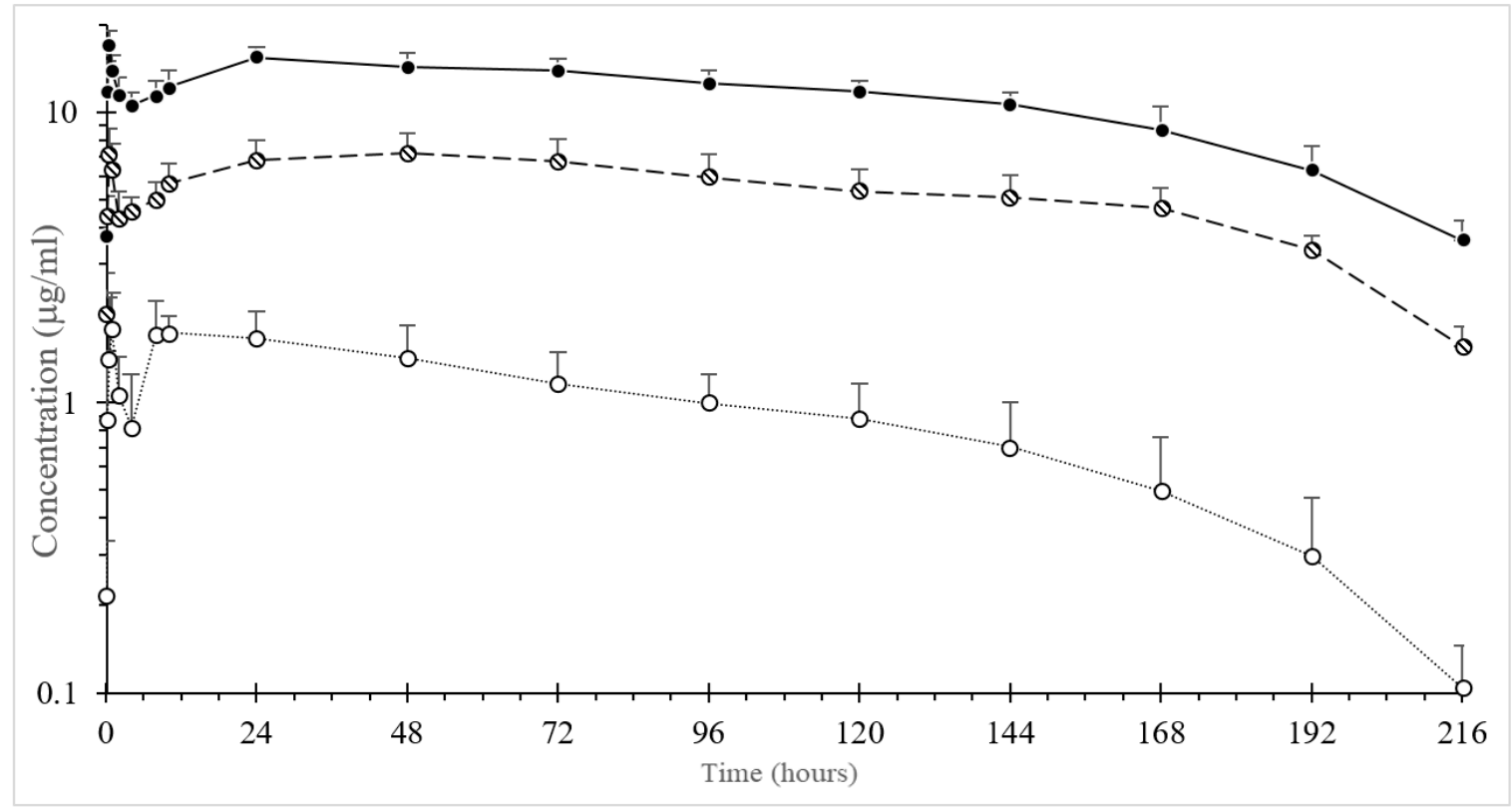

Figure 1. Semi-log average $( \pm S D)$ plasma concentration versus time curve of long-acting formulation oxytetracycline after intramuscular administration at three different dosages of $5 \mathrm{mg} / \mathrm{kg}$ body weight

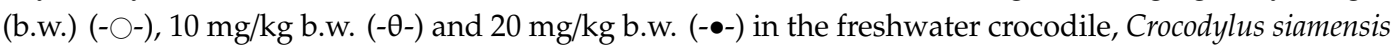
$(n=5)$. Error bars indicate standard deviation.

The value for $t_{1 / 2 \lambda z}$ was significantly shorter in the $5 \mathrm{mg} / \mathrm{kg}$ b.w. group compared to the 10 and $20 \mathrm{mg} / \mathrm{kg}$ b.w. groups, where the results were almost identical. The mean $( \pm \mathrm{SD})$ pharmacokinetic parameters of OTC are reported in Table 1. The average value of the plasma protein-binding percentage of OTC was $32.69 \% \pm 9.16 \%$.

Table 1. Mean \pm SD values of the pharmacokinetic parameters of the long-acting formulation of oxytetracycline (OTC-LA) following intramuscular administration at three different dosages $(5,10$ and $20 \mathrm{mg} / \mathrm{kg}$ body weight (b.w.)) in the freshwater crocodile, Crocodylus siamensis ( $n=5$ per group).

\begin{tabular}{|c|c|c|c|}
\hline \multirow{2}{*}{ Pharmacokinetic Parameter (Unit) } & \multicolumn{3}{|c|}{ OTC-LA } \\
\hline & $5 \mathrm{mg} / \mathrm{kg}$ & $10 \mathrm{mg} / \mathrm{kg}$ & $20 \mathrm{mg} / \mathrm{kg}$ \\
\hline $\mathrm{C}_{\max }(\mu \mathrm{g} / \mathrm{mL})$ & $2.15 \pm 0.51$ & $7.68 \pm 1.08^{\mathrm{ac}}$ & $17.08 \pm 2.09 \mathrm{ab}$ \\
\hline $\mathrm{T}_{\max }(\mathrm{h}) \S$ & $1.0(0.5-8.0)$ & $0.5(0.5-1.0)$ & $0.50(0.00)$ \\
\hline$\lambda_{\mathrm{z}}\left(\mathrm{h}^{-1}\right)$ & $0.021 \pm 0.001$ & $0.018 \pm 0.002$ & $0.018 \pm 0.001$ \\
\hline $\mathrm{t}_{1 / 2 \lambda}(\mathrm{h})$ & $33.59 \pm 2.51$ & $38.42 \pm 5.47^{\mathrm{a}}$ & $38.04 \pm 1.98^{\mathrm{a}}$ \\
\hline $\mathrm{AUC}_{\text {last }}(\mathrm{h} \mathrm{mg} / \mathrm{L})$ & $199.27 \pm 51.91$ & $1101.36 \pm 164.54 \mathrm{ac}$ & $2405.15 \pm 182.37 \mathrm{ab}$ \\
\hline $\mathrm{AUC}_{0-\infty}(\mathrm{h} \mathrm{mg/L})$ & $206.96 \pm 54.56$ & $1196.05 \pm 159.93^{\mathrm{ac}}$ & $2611.76 \pm 196.08^{a b}$ \\
\hline $\mathrm{C}_{\max } /$ dose & $0.43 \pm 0.10$ & $0.77 \pm 0.11$ & $0.85 \pm 0.10$ \\
\hline AUC/dose & $39.85 \pm 10.38$ & $110.14 \pm 16.45^{\mathrm{a}}$ & $120.26 \pm 9.12^{\mathrm{a}}$ \\
\hline $\mathrm{MRT}_{\text {last }}(\mathrm{h})$ & $76.36 \pm 8.79$ & $93.55 \pm 2.72^{\mathrm{a}}$ & $92.03 \pm 3.01^{\mathrm{a}}$ \\
\hline
\end{tabular}

Note: $C_{\max }=$ peak plasma concentration, $\mathrm{T}_{\max }=$ time of peak concentration, $\lambda \mathrm{z}=$ terminal phase rate constant, $\mathrm{t}_{1 / 2 \lambda}=$ terminal half-life, $\mathrm{AUC}_{\text {last }}=$ area under the curve from 0 to the last point of drug quantification, $\mathrm{AUC}_{0-\infty}$ $=$ area under the curve from $0 \mathrm{~h}$ to infinity and $\mathrm{MRT}_{\text {last }}=$ mean residence time from 0 to the last point of drug quantification. $p<0.05{ }^{a}=$ significant difference from the group that received OTC-LA intramuscularly at a dosage of $5 \mathrm{mg} / \mathrm{kg}$ b.w., ${ }^{b}=$ significant difference from the group that received OTC-LA intramuscularly at a dosage of $10 \mathrm{mg} / \mathrm{kg}$ b.w. and ${ }^{\mathrm{c}}=$ significant different from the group that received OTC-LA intramuscularly at a dosage of $20 \mathrm{mg} / \mathrm{kg}$ b.w. $\S=$ median value and range. 
A linear relationship between dose and AUC or $C_{\max }$ was found between 10 and $20 \mathrm{mg} / \mathrm{kg}$ b.w. but not for the $5 \mathrm{mg} / \mathrm{kg}$ b.w. treatment.

\section{Discussion}

The study was designed to characterize the pharmacokinetic features of OTC-LA after i.m. administration at dosages of 5,10 and $20 \mathrm{mg} / \mathrm{kg}$ b.w. in the freshwater crocodile, C. siamensis. A few published papers have described the pharmacokinetics of antibacterial drugs in reptilian species-namely, American alligators, estuarine crocodiles and freshwater crocodiles [5-11]. However, to date, there have been no reports on the pharmacokinetics of OTC in the freshwater crocodile, C. siamensis. In addition, drug dosages in freshwater crocodiles are often extrapolated from domestic animals or members of similar taxonomic orders, but even careful allometric scaling based on similar species can result in unpredictable pharmacokinetic profiles and toxicoses [16]. In the present study, the critical pharmacokinetic parameters were evaluated after i.m. administration at three different dosages.

Plasma concentrations after OTC-LA administration were quantifiable up to $216 \mathrm{~h}$ after i.m. administration at dosages of 5, 10 and $20 \mathrm{mg} / \mathrm{kg}$ b.w. OTC was rapidly detected in plasma, with a first peak at $0.5-1.0 \mathrm{~h}$; then, the concentration dropped rapidly, and subsequently, a second peak (24-48 h) occurred, followed by the gradual decline of the drug in the plasma circulation. This profile has been earlier reported in alligators [5] and fish [17]. In fish, it was speculated to have been due to drug reabsorption via the skin, but this was unlikely in the present study, because crocodile skin is very hard for a drug to penetrate [17], and any drug eliminated in the water would have been diluted at a negligible concentration due to the large volume of water in the holding pond. In alligators [5], this peculiar PK profile has been hypothesized to be due to OTC-LA formulation, with a portion acting immediately (the first peak), followed by a depot effect (the second peak) [5]. The ability of OTC-LA to generate inflammation in the tissue is injected. In such a case, the OTC might be rapidly adsorbed until the inflammation takes place; then, due to homeostasis, the drug is no longer able to enter the blood circulation at the same rate; then, as the inflammation is slowly resolved, the drug concentration rises again (the second peak).

The $t_{1 / 2 \lambda}$ value of OTC obtained in the freshwater crocodiles was long and almost identical following i.m. administration after two dosages of 10 and $20 \mathrm{mg} / \mathrm{kg} \mathrm{b.w.} \mathrm{This} \mathrm{indicated} \mathrm{that} \mathrm{the}$ overall rate of elimination of OTC in freshwater crocodiles was slow. The long $t_{1 / 2 \lambda_{z}}$ reported here was consistent with the low elimination rate constant and the slow clearance rate. However, the mean $t_{1 / 2 \lambda z}$ value was shorter than that reported in American alligators (approximately $131 \mathrm{~h}$ ) [5]. These differences might have resulted from species-specific differences, different environmental temperatures during the experiment, the time of blood collection or different sensitivities in the analytical methods [18]. Accordingly, the MRT values in the present investigation were shorter than those reported in American alligators $(254 \mathrm{~h})$ [5]. In the present study, the average percentage of protein binding of OTC in the freshwater crocodile plasma was moderate $(32.69 \%)$, although, to date, no comparative value for this parameter has been reported in reptiles. The pharmacokinetics of OTC in this species are dose-dependent, between 10 and $20 \mathrm{mg} / \mathrm{kg}$. In contrast, a nonlinear relationship between the dose and AUC or $C_{\max }$ was shown with the $5 \mathrm{mg} / \mathrm{kg}$ dose. Further studies are warranted to explain this finding.

High plasma OTC concentrations were found in freshwater crocodiles after i.m. administration at dosages of 10 and $20 \mathrm{mg} / \mathrm{kg}$ b.w. The MIC value for OTC is about $0.25-2.0 \mu \mathrm{g} / \mathrm{mL}$ for most susceptible microorganisms that can cause significant diseases in animal species [19]. The Clinical Laboratory Standard Institute (CLSI) suggests a cut-off value ranging from 0.25 to $2.0 \mu \mathrm{g} / \mathrm{mL}$ for tetracycline susceptibility depending upon both the bacterial (mammalian pathogens) and animal species (mammalian). CLSI standards for the interpretation of bacteria isolated from animals does not contain breakpoints for the interpretation of susceptibility test results for OTC in reptiles. Due to inter- and intraspecies differences between animals, it is necessary to specify the dosage regimen for the prudent use of antibiotics in each animal species. The AUC/MIC ratio can be used as a predictor of antibacterial success in clinical subjects, since OTC is classified as a bacteriostatic agent [20]. Studies 
performed in other animal species show that a favorable therapeutic target is AUC/MIC $>25$. Bacteria considered "susceptible" in other animals have MIC values of $2 \mu \mathrm{g} / \mathrm{mL}$ or less [19]. Based on this value, the dose administered to crocodiles reached the target for AUC (truncated to $24 \mathrm{~h}$ ) for bacteria with $\mathrm{MIC}$ values $\leq 3.8$ and $8.6 \mu \mathrm{g} / \mathrm{mL}$ for 10 and $20 \mathrm{mg} / \mathrm{kg}$ b.w., respectively. Although the AUC/MIC ratio achieved in this study was high (ratio $>900$ for the highest dose), this was the entire AUC to infinity. AUC/MIC targets for mammals are calculated for only a 24-h interval, whereas the concentrations in this study were above a MIC value of $2 \mu \mathrm{g} / \mathrm{mL}$ for over 15 days. All the PK/PD calculations were performed considering the percentage protein binding of the OTC obtained in this study. Studies on clinically infected crocodiles warranted a confirmation of this data. Notably, the OTC plasma concentration was not achieved and did not remain above the MIC of $2.0 \mu \mathrm{g} / \mathrm{mL}$ at a dosage of $5 \mathrm{mg} / \mathrm{kg}$ b.w. However, the MIC values of the important bacterial pathogens that affect freshwater crocodiles should be examined for the efficacious use of OTC in freshwater crocodiles.

Author Contributions: S.P., methodology, formal analysis and validation; N.K., N.P. and T.W., sample collection, animal preparation and visualization; N.C., conceptualization and supervision; M.G., conceptualization, P.K., analysis, validation, supervision and editing; D.J.T., validation, supervision and editing and A.P., conceptualization, funding acquisition, sample collection, methodology, validation, supervision, project administration and writing (reviewing and editing). All authors have read and agreed to the published version of the manuscript.

Funding: This work was funded by the Thailand Research Fund, Bangkok, Thailand (research grant number: RSA6180033) and the Kasetsart University Research and Development Institute (KURDI), Bangkok, Thailand. The authors thank ThothPro for supplying the ThothPro software $(4.3 .0 \mathrm{v})$.

Conflicts of Interest: The authors declare no conflicts of interest.

\section{References}

1. Bywater, R.J. Veterinary Applied Pharmacology and Therapeutics; Bailliere Tindal: London, UK, 1991.

2. Chopra, I.; Roberts, M. Tetracycline antibiotics: Mode of action, applications, molecular biology, and epidemiology of bacterial resistance. Microbiol. Mol. Biol. Rev. 2001, 65, 232-260. [CrossRef]

3. Adir, J. Enterohepatic circulation of tetracycline in rats. J. Pharm. Sci. 1975, 64, 1847-1850. [CrossRef]

4. Huchzermeyer, F.W. Diseases of farmed crocodiles and ostriches. Rev. Sci. Tech. Off. Int. Epiz. 2002, 21, 265-276. [CrossRef] [PubMed]

5. Helmick, K.E.; Papich, M.G.; Vliet, K.A.; Bennett, R.A.; Jacobson, E.R. Pharmacokinetic disposition of a long-acting oxytetracycline formulation after single-dose intravenous and intramuscular administrations in the American alligator (Alligator mississippiensis). J. Zoo Wildl. Med. 2004, 35, 341-346. [CrossRef] [PubMed]

6. Martelli, P.; Lai, O.R.; Krishnasamy, K.; Predo Marin, E.L.; Laricchiuta, P.; Crescenzo, G. Pharmacokinetic behavior of enrofloxacin in Estuarine crocodile (Crocodylus porosus) after single intravenous, intramuscular, and oral doses. J. Zoo Wildl. Med. 2009, 40, 696-704. [CrossRef] [PubMed]

7. Rivera, S.; Nevarez, J.G.; Maxwell, L.K.; Barker, S.A. Pharmacokinetics of tetracycline after single-dose oral administration in the American alligator (Alligator mississippiensis). J. Zoo Wildl. Med. 2012, 43, 858-863. [CrossRef] [PubMed]

8. Poapolathep, S.; Giorgi, M.; Hantrakul, S.; Klangkaew, N.; Sanyathitiseree, P.; Poapolathep, A. Pharmacokinetics of marbofloxacin in freshwater crocodiles (Crocodylus siamensis) after intravenous and intramuscular administration. J. Vet. Pharm. Ther. 2017, 40, 57-61. [CrossRef] [PubMed]

9. Poapolathep, S.; Giorgi, M.; Chaiyabutr, N.; Klangkaew, N.; Phaochoosak, N.; Wongwaipirote, T.; Poapolathep, A. Pharmacokinetics of ceftriaxone in freshwater crocodiles (Crocodylus siamensis) after intramuscular administration at two dose rates. J. Vet. Pharm. Ther. 2020, 43, 141-146. [CrossRef] [PubMed]

10. Poapolathep, S.; Giorgi, M.; Chaiyabutr, N.; Chokecharoenrat, C.; Klangkaew, N.; Phaochoosak, N.; Wongwaipairote, T.; Poapolathep, A. Pharmacokinetics of enrofloxacin and its metabolite ciprofloxacin in freshwater crocodiles (Crocodylus siamensis) after intravenous and intramuscular administration. J. Vet. Pharm. Ther. 2020, 43, 19-25. [CrossRef] [PubMed]

11. Poapolathep, S.; Giorgi, M.; Klangkaew, N.; Phaochoosak, N.; Chaiyabutr, N.; Wongwaipairoj, T.; Poapolathep, A. Pharmacokinetic profiles of amoxicillin trihydrate in freshwater crocodiles (Crocodylus siamensis) after intramuscular administration at two doses. J. Vet. Pharm. Ther. 2020, 43, 307-312. [CrossRef] [PubMed] 
12. Escudero, E.; Carceles, C.M.; Serrano, J.M. Pharmacokinetics of oxytetracycline in goats: Modifications induced by a long-acting formulation. Veter. Rec. 1994, 135, 548-552.

13. Sun, Y.; Peng, Y.; Aksornkoae, N.; Johnson, J.R.; Gregg Boring, J.; Scruggs, D.; Cooper, R.C.; Casey Laizure, S.; Shukla, A.J. Controlled release of oxytetracycline in sheep. J. Cont. Release. 2002, 85, 125-134. [CrossRef]

14. Poapolathep, S.; Wongpanit, K.; Imsilp, K.; Tanhan, P.; Klangkaew, N.; Giorgi, M.; Poapolathep, A. Disposition of a long-acting oxytetracycline formulation in Thai swamp buffaloes (Bubalus bubalis). J. Vet. Pharm. Ther. 2017, 40, 206-209. [CrossRef] [PubMed]

15. Mapongpeng, R.; Laovechprasit, W.; Poapolathep, A.; Giorgi, M.; Junchompoo, C.; Sakulthaew, C.; Jermnak, U.; Passadurak, W.; Poapolathep, S. Pharmacokinetics of ceftriaxone in Green sea turtles (Chelonia mydas) following intravenous and intramuscular administration at two dosages. J. Vet. Pharm. Ther. 2019, 42, 104-110. [CrossRef] [PubMed]

16. Hunter, R.P.; Isaza, R. Concepts and issues with interspecies scaling in zoological pharmacology. J. Zoo Wildl. Med. 2008, 39, 517-526. [CrossRef] [PubMed]

17. Rigos, G.; Smith, P. A critical approach on pharmacokinetics, pharmacodynamics, dose optimisation and withdrawal times of oxytetracycline in aquaculture. Rev. Aquac. 2015, 7, 77-106. [CrossRef]

18. Toutain, P.L.; Bouqsuet-Melou, A. Plasma terminal half-life. J. Vet. Pharm. Ther. 2004, 27, 427-439. [CrossRef] [PubMed]

19. Clinical Laboratory Standard Institute (CLSI). VET08: Performance Standards for Antimicrobial Disk and Dilution Susceptibility Tests for Bacteria Isolated from Animals, 4th ed; CLSI: Wayne, PA, USA, 2018.

20. Brentnall, C.; Cheng, Z.; McKellar, Q.A.; Lees, P. Pharmacokinetic-pharmacodynamic integration and modelling of oxytetracycline administered alone and in combination with carprofen in calves. Res. Vet. Sci. 2013, 94, 687-694. [CrossRef] [PubMed]

(C) 2020 by the authors. Licensee MDPI, Basel, Switzerland. This article is an open access article distributed under the terms and conditions of the Creative Commons Attribution (CC BY) license (http://creativecommons.org/licenses/by/4.0/). 